\title{
Design and Analysis Effect of Gantry Angle Photon Beam 4 MV on Dose Distributions using Monte Carlo Method EGSnrc Code System
}

\author{
Uum Yuliani $^{1^{*}}$, Ridwan Ramdani ${ }^{1}$, Freddy Haryanto ${ }^{2}$, Yudha Satya Perkasa $^{1}$, Mada Sanjaya $^{1}$ \\ ${ }^{1}$ Physics Laboratory Modeling Faculty of Sains and Tecnology, State Islamic University Sunan Gunung Djati, St.A.H. \\ Nasution No.105, Bandung 40614, Indonesia \\ ${ }^{2}$ Physics Laboratory Nuclear Faculty of Math and Science Institute of Technology, S.t Ganesha No.10, Bandung 40132, \\ Indonesia
}

Received: 27 March 2016, Revised: 12 April 2016, Accepted: 9 June 2016

\begin{abstract}
Varian linac modeling has been carried out to obtain Percentage Depth Dose (PDD) and profiles using variations gantry angle $0^{\circ}, 15^{\circ}, 30^{\circ}, 45^{\circ}$ in the vertical axis of the surface, field size $10 \times 10 \mathrm{~cm}^{2}$, photon beam 4 MV and Monte Carlo simulations. Percentage Depth Dose and profile illustrates dose distributions in a phantom water measuring $40 \times 40 \times 40$ $\mathrm{cm}^{3}$, changes gantry is one of the factors that determine the distribution of the dose to the patient research shows changes in Dmax in the Percentage Depth Dose is affected by changes in the angle gantry resulted in the addition of the area build up so it can be used for therapy in the region and produce skin sparing effects that can be used to protect the skin from exposure to radiation. The graph result is profiles obtained show lack simetrisan in areas positive quadrant has a distribution of fewer doses than the quadrant of negative as well as the slope of the surface so that it can be used for some cases treatments that require a depth and a certain slope, dose calculations are more accurate and can minimize side effects.
\end{abstract}

Keywords: Plane Varian Linac, Percentage Depth Dose, Profile, Gantry, and Monte Carlo.

\section{INTRODUCTION}

Cancer is cell that change undergoing abnormal growth, uncontrolled and included the most dreaded diseases [1], Radiotherapy is a type of cancer treatment that uses radiation, it sources can be obtained from artificial or natural light. One of the tools used in radiotherapy is the best LINAC (Linear Accelerator), which serves to accelerate charged particles in radiation therapy maximum dose obtained should be right in the cancer tissue and the tissue healthy got a very low dose to avoid side effects on healthy tissue, the process calibration and therapy planning system to Linac using Monte carlo modeling.

Previous studies have been conducted by Agung Nugroho Oktavianto in 2010 using the best Linac Electa precise variation gantry, a wide variation of pitch, X-ray beam $6 \mathrm{MV}$, with reconstruction TPS and simulation monte carlo right to a certain angle must not exceed the broad field $15 \times 15 \mathrm{~cm}^{2}$ and $30 \times 30 \mathrm{~cm}^{2}$ [2], in this experimet I use the comprehensive updates using a $10 \times 10 \mathrm{~cm}^{2}$ field.

\section{THEORY/CALCULATION}

Linac is a tool used to accelerate the particles used for the treatment of cancer using radiation sources with the principle of providing maximum dose in cancer cells and minimized in healthy cells at around [3].

the photon beam of high-energy electron beam is passed to the target. The target is brake by an accelerated electrons generate Bremsstrahlung. Bremsstrahlung photons with energy spectrum is

\footnotetext{
1 Corresponding author.
}

E-mail address: uum.yuliani22@gmail.com 
continuous. Creation of a photon having a high intensity in the direction of the axis of the target. The maximum energy of the photon will be equal to the energy of electrons coming fired at the target. The Photon will be forwarded past the Primary collimator toward the carrousel. Part carrousel will issue flattering filter. It made from stainless steel are designed to achieve flatness is required. Then photons it results forwarded to the ion chamber to form the dose of photons in the number of Monitor Unit (MU). Then forwarded to the secondary collimator to get more photons in the MU flat. The final results will be out of the photons in the linac called gantry, which rotates around the patient.

Monte Carlo (MC) is a method that uses the principle of random numbers that are well suited to simulate the interactions of particles that are stochastic. Monte Carlo describes the life of the particle, the particles ranging from the birth, life to death. One of thevprogram that uses the Monte Carlo method EGS Code System with new version of EGSnrc, EGSnrc is quite easy to use with Graphical User Interface (GUI) [5]. EGSnrc has several user code, including BEAMnrc for particle transport simulation on geometry and radiation treatment head DOSXYZnrc formodeling particle transport in voxel phantom which has been prepared in a $3 \mathrm{D}$ direction.

\section{EXPERIMENTAL METHOD}

Make the design of linac head can be done in software BEAMnrc output processing using BEAMDP, BEAMDP output can be used for analysis of the results of running BEAMnrc phase space in the form of data files (phsp). DOSXYZnrc can be used to design a phantom to see how the dose distribution in the phantom. Then do the survey parameters in this study used a variation of the gantry angle to see the effect on the distribution of the dose.

\section{RESULTS AND DISCUSSION}

It has been made head of design variants linac $4 \mathrm{MV}$ photon energy, broad field $10 \times 10 \mathrm{~cm} 2$, and variations gantry $0 \circ, 15^{\circ}, 30^{\circ}$ and $45^{\circ}$ using a program that requires BEAMnrc then simulated particle history and time.

Table 1. Time Simulation Head Linac

\begin{tabular}{cccl}
\hline Simulation & Half life & Simulation Time & Information \\
\hline Head Linac section 1 & 14.3 days & 20,526 Hour & Serial 1 core \\
Head Linac section 1 & 25 days & 123,156 Hour & Serial 1 core
\end{tabular}

\begin{tabular}{|c|c|c|c|}
\hline Head Linac section 1 & 5,730 years & 61,578 Hour & Serial 1 core \\
\hline Head Linac section 2 & 12.3 years & $\begin{array}{c}\text { 41,3 Hour/1,7 } \\
\text { Day }\end{array}$ & $\begin{array}{l}\text { Serial } 8 \text { core } \\
\text { parallel }\end{array}$ \\
\hline Total Head Linac & 87.4 days & 10 Day & \\
\hline
\end{tabular}

Table 2. Time Simulation Phantom

\begin{tabular}{|c|c|c|c|}
\hline Simulation & History Particle & Simulation Time & Information \\
\hline $\begin{array}{l}\text { Phantom with } \\
\text { directions Gantri } 0 \\
\text { degrees }\end{array}$ & 1 Billion & 1,5 Hour & $\begin{array}{l}\text { Serial } 8 \text { core } \\
\text { parallel }\end{array}$ \\
\hline $\begin{array}{c}\text { Phantom with } \\
\text { directions Gantry } 15 \\
\text { degrees }\end{array}$ & 1 Billion & 1,5 Hour & $\begin{array}{l}\text { Serial } 8 \text { core } \\
\text { parallel }\end{array}$ \\
\hline $\begin{array}{c}\text { Phantom with } \\
\text { directions Gantry } 30 \\
\text { degrees }\end{array}$ & 1 Billion & 1,5 Hour & $\begin{array}{c}\text { Serial } 8 \text { core } \\
\text { parallel }\end{array}$ \\
\hline $\begin{array}{c}\text { Phantom with } \\
\text { directions Gantry } 45 \\
\text { degrees }\end{array}$ & 1 Billion & 1,5 Hour & $\begin{array}{l}\text { Serial } 8 \text { core } \\
\text { parallel }\end{array}$ \\
\hline
\end{tabular}

So come by fluence distrubution and its energy as photon beam characteristics of these characteristics that can not be seen in the direct

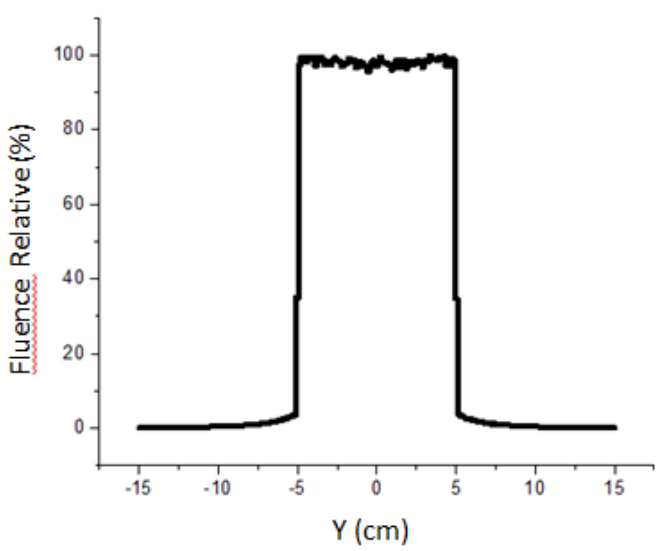

Fig. 1. Fluence to position.

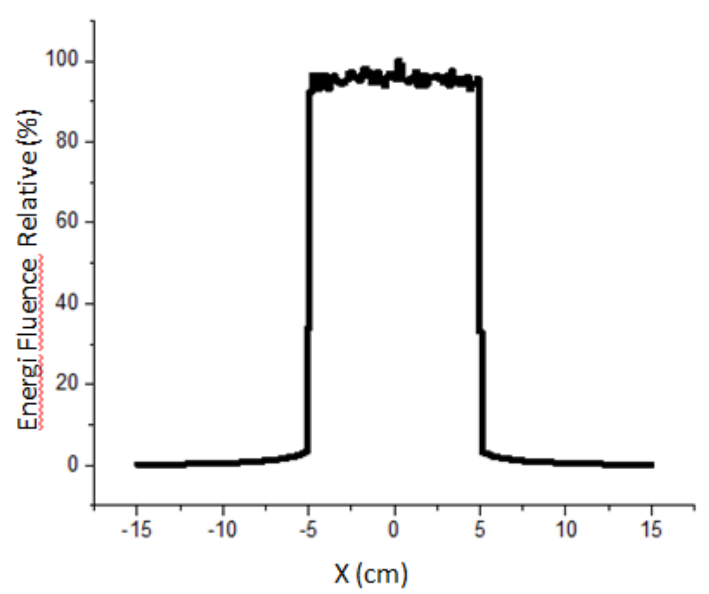

Fig. 2. Energy Fluence to position. 
phantom creation to the size of $40 \times 40 \times 40 \mathrm{~cm}^{3}$ of water $\left(\mathrm{H}^{2} \mathrm{O}\right)$ using DOSXYZnrc and changes gantry so as to obtain results Percentage Depth Dose to the $\mathrm{z}$-axis and the profile for the $\mathrm{XY}$ axis in order to get the following curve:

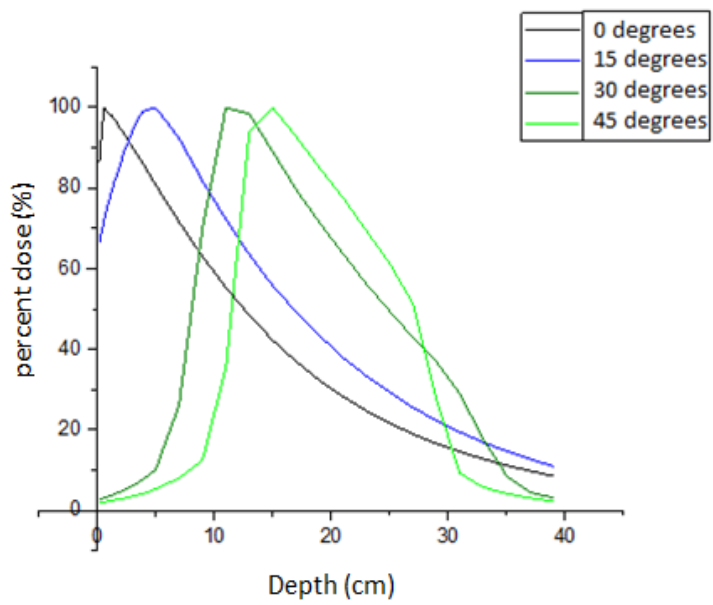

Fig. 3. PDD with changes gantry

it can be seen from the graph above the maximal dose changes with depth look quite striking changes to make it easier we can see in the following table:

Table 3. Changescorner of the maximum dose

\begin{tabular}{ccc}
\hline No & Angle $\left({ }^{\circ}\right)$ & Dmax $(\mathrm{cm})$ \\
\hline 1 & 0 & 0,6 \\
2 & 15 & 5 \\
3 & 30 & 11 \\
4 & 45 & 15 \\
\hline
\end{tabular}

the results showed changes in the Percentage Depth dose Dmax which is affected by changes resulting in additional gantry angle, the build up area so that it can used for therapy in the area.

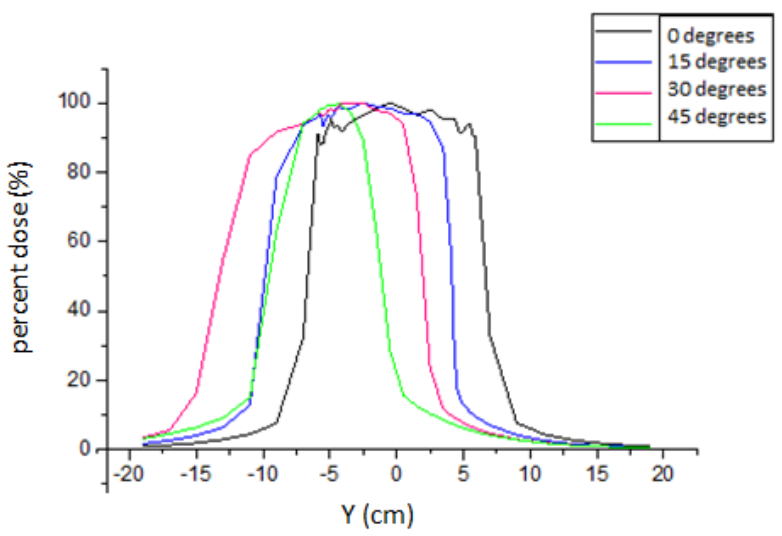

Fig. 4. Profile with changes gantry

the profile graph results obtained show lack symetry the positive quadrant area has distribution fewer doses than the quadrant of negative as well as the slope of the surface so that it can be used for some cases treatments that require a depth and a certain slope,

in fact in cases radiotherapy requires not only a radiation flat or require a certain slope to protect healthy tissue because the cancer cells are in the blood that are difficult to reach and located near vital organs so that this data can be used as comparative data in radiotherapy.

\section{CONCLUSION}

the linac head procedure designs using energy photon $4 \mathrm{MV}$ model Varian Clinac iX, spacious $10 \times 10 \mathrm{~cm}^{2}$ field, the head of his linac simulated using BEAMnrc program, and using a water phantom measuring 40x40x $40 \mathrm{~cm}^{3}$ simulated using DOSXYZnrc. With gantry variation of $0^{\circ}, 15^{\circ}, 30^{\circ}, 45^{\circ}, 60^{\circ}$ resulting in depth dmax in PDD and nuisance symmetry major axis of the profile so that it can be used for cases of radiation on sloping areas to protect healthy tissue or reduce the risk.

\section{ACKNOWLEDGMENT}

The authors would like to thank the Department of Physics Faculty of Sciences and technology which has been financed by a grant thesis and Roger Soh from the School of Physical and Mathematical Sciences, Nanyang Technological University Singapore on data sheet Linac Varian Clinac IX.

\section{REFERENCES}

[1] Ericka, W and George, R. Radiaton- Induced Lung Injury, Strategies for Reducing Therapeutic Dosage. Parkhurst: PA Management, 2006.

[2] Oktavianto, Agung Nugroho. Measurement and Simulation Monte Carlo Percentage Depth Dose 6 MV X-ray Files Falling On Sloping Field: Verify TPS. Depok: University of Indonesia, 2010.

[3] Podogorsak, E.B. Chapter 5 Treatment Machines for External Beam Radiotherapy. Canada : Departement of Medical Physics McGiil University health Center.

[4] Anonim. The Radiology information resource for patients. Radiology.org. 2013.

[5] Kawrakow, I.et.al. The EGSnrc Code System: Monte Carlo Simulation of Electron and Photon Transfort. National Research Council of Canada, 2013. 